\title{
High-resolution DLTS of vacancy-donor pairs in P-, As- and Sb-doped silicon
}

\author{
F.D. Auret, A.R. Peaker, V.P. Markevich, L. Dobaczewski and R.M. Gwilliam
}

\begin{abstract}
We report results from an experiment designed to characterize, by high-resolution (Laplace) DLTS, the electronic properties of electron radiation induced E-centers in $\mathrm{Si}$ associated with P, Sb and As. Four sets of samples that contained (i) only P, (ii) P and Sb, (iii) $\mathrm{P}$ and $\mathrm{As}$, and (iv) $\mathrm{P}, \mathrm{Sb}$ and As were used. In the sample containing only $\mathrm{P}$, the activation energy of electron emission from the single acceptor level of V-P in silicon was found to be $(0.458 \pm 0.005) \mathrm{eV}$. For the sample with $\mathrm{P}$ and $\mathrm{Sb}$, the Laplace peaks of the $\mathrm{V}-\mathrm{Sb}$ and $\mathrm{V}-\mathrm{P}$ were clearly separated and the ratio of their emission rates was always $>4$. The energy levels extracted were $(0.401 \pm 0.01)$ and $(0.442 \pm 0.01) \mathrm{eV}$ for the $\mathrm{V}-\mathrm{Sb}$ and V-P, respectively. The levels calculated for V-P in these two samples can be considered to be, within the experimental error, the same. In the sample with As and $\mathrm{P}$, the ratio of the emission rate of $\mathrm{V}-\mathrm{As}$ to $\mathrm{V}-\mathrm{P}$ was 1.8 and the result was that, although the $\mathrm{V}-\mathrm{As}$ and $\mathrm{V}-\mathrm{P}$ peaks could clearly be split, there is some inaccuracy in their calculated energy level positions of $(0.435 \pm 0.005)$ and $(0.434 \pm 0.01) \mathrm{eV}$, respectively. In the sample containing all three dopants, the peaks of $\mathrm{V}-\mathrm{P}, \mathrm{V}-\mathrm{Sb}$ and $\mathrm{V}-\mathrm{As}$ could be separated but the DLTS "signatures" of these E-centers differed significantly from those where only one or two E-centers were present.
\end{abstract}

\section{Article Outline}

1. Introduction

2. Experimental procedure

3. Results and discussion

4. Conclusions and summary

Acknowledgements

References

\section{Introduction}

Achieving very high $n$-type doping levels in silicon has recently prompted renewed interest in donor-related defects, e.g. the donor-vacancy complexes (E-centers), and necessitated an understanding of their electronic and thermal behaviour. The electronic properties of the various E-centers, depending on the dopant involved, have been reported and the level positions below the conductions band range from 0.40 for the $\mathrm{V}-\mathrm{Sb}$ center 
to 0.45 for $\mathrm{V}-\mathrm{P}$ [1], [2] and [3]. In these studies the different E-centers were studied in different Si wafers, each doped with only one dopant. Because these levels lie so close together, conventional deep-level transient spectroscopy (DLTS) cannot be used to study different E-centers in the same sample.

In the meanwhile high-resolution Laplace DLTS [4] has emerged as a powerful new tool for thermal emission studies because of its much improved spectral resolution compared to conventional techniques [5]. Under ideal conditions Laplace DLTS can resolve defect levels of which the emission rates differ by a factor of 2 . In this paper, we demonstrate how Laplace DLTS can be used to characterize different E-centers that are present in the same sample.

\section{Experimental procedure}

The starting material for this study was $\left(\begin{array}{lll}1 & 0 & 0\end{array}\right) 5^{\prime \prime}$ diameter epitaxial Si. The epitaxial Pdoped $n$-layer with a free carrier concentration of $1.1 \times 10^{16} \mathrm{~cm}^{-3}$ and $6 \mu \mathrm{m}$ thick was grown by a commercial vendor using chemical vapour deposition (CVD) on $\mathrm{n}^{2+}$ substrate. The wafer was diced into quarters, S1-S4. The first quarter, S1, was used as a control and received no implantation. Two of the four quarters, S2 and S3, were implanted with As and Sb, respectively, to yield As and Sb concentrations of (8$9) \times 10^{15} \mathrm{~cm}^{-3}$. The fourth quarter, S4, was implanted with both As and Sb, to yield concentrations of $(8-9) \times 10^{15} \mathrm{~cm}^{-3}$ for both dopants. After implantation the Si samples were annealed at $950{ }^{\circ} \mathrm{C}$ for $30 \mathrm{~min}$ in nitrogen to activate the dopants and to remove implantation-induced disorder in the Si. The implantation was carried in such a way as to produce a uniform dopant profile in the first $1.2 \mu \mathrm{m}$ below the surface by performing a set of implantations at different energies.

Subsequent to this, the four Si quarters wafers were irradiated by high-energy $(3.5 \mathrm{MeV})$ electrons to doses of $5 \times 10^{15} \mathrm{~cm}^{-2}(\mathrm{~S} 1)$ and $1.5 \times 10^{16} \mathrm{~cm}^{-2}$ (S2-S4), as summarized in Table 1. Next, the wafers were cut up into $5 \times 3 \mathrm{~mm}$ samples for Schottky barrier diode (SBD) fabrication. Immediately after chemical cleaning Au Schottky contacts, $1 \mathrm{~mm}$ in diameter, were deposited in vacuum by Joule evaporation on the implanted sides of the samples and then $\mathrm{Al}$ was deposited on their $\mathrm{n}^{2+}$ backsides as ohmic contacts. The quality of the SBDs was assessed by current-voltage $(I-V)$ measurements and the free carrier concentrations of the $n$-layers were determined by capacitance-voltage $(C-V)$ measurements. The $C-V$ results thus obtained are included in Table 1 . The irradiationinduced defects in the samples were characterized by conventional as well as highresolution Laplace DLTS. 
Table 1.

Ion implantation and electron irradiation of P-doped $n$-Si

\begin{tabular}{|l|l|l|l|l|}
\hline $\begin{array}{l}\text { Sample } \\
\text { ID }\end{array}$ & $\begin{array}{l}\text { Implanted } \\
\text { ion }\end{array}$ & $\begin{array}{l}\text { Extent of } \\
\text { implant }(\boldsymbol{\mu m})\end{array}$ & $\boldsymbol{N}_{\mathbf{D}}\left(\mathbf{c m}^{-\mathbf{3}}\right)$ & $\begin{array}{l}\text { Electron irradiation } \\
\left.\text { dose } \mathbf{( c m}^{-2}\right)\end{array}$ \\
\hline S1 (no0) & - & - & $(1.1 \pm 0.1) \times 10^{16}$ & $5.0 \times 10^{15}$ \\
\hline S2 (no8) & Sb & 1.2 & $(2.0 \pm 0.1) \times 10^{16}$ & $1.5 \times 10^{16}$ \\
\hline S3 (no6) & As & 1.2 & $(2.0 \pm 0.1) \times 10^{16}$ & $1.5 \times 10^{16}$ \\
\hline S4 (no7) & As and Sb & 1.2 & $(3.0 \pm 0.1) \times 10^{16}$ & $1.5 \times 10^{16}$ \\
\hline
\end{tabular}

\section{Results and discussion}

Fig. 1 depicts conventional DLTS spectra of the samples from structures S1-S4. The most prominent peaks in these spectra are due to the $\mathrm{V}-\mathrm{O}$ (A-center) at about $85 \mathrm{~K}$, the $\mathrm{V}-\mathrm{V}^{0 /-}$ at $130 \mathrm{~K}$ and the superposition of the $\mathrm{V}-\mathrm{V}^{=/-}$and $\mathrm{E}-$ center(s) at $220-230 \mathrm{~K}$. It can be seen that the $\mathrm{V}-\mathrm{O}$ center is more prominent in the implanted and annealed layers than in the as-grown material. This is due to the diffusion of oxygen from the Czochralski substrate into the oxygen lean epitaxial layer during the $950{ }^{\circ} \mathrm{C} 30 \mathrm{~min}$ anneal. The diffusivity is likely to be enhanced by the implant damage [6]. For the E-centers in Fig. 1 we have used the nomenclature $\mathrm{V}-D$, where $D=\mathrm{P}, \mathrm{As}, \mathrm{Sb}$ or combinations of them. Since the magnitudes of the $\mathrm{V}-\mathrm{V}^{0 /-}$ and $\mathrm{V}-\mathrm{V}^{=/-}$concentrations are the same for electron irradiation, Fig. 1 shows that the main contribution to the peak at $220 \mathrm{~K}$ will be from the E-centers and further that the ratio of the E-center to that of the divacancy in this peak will be at least 5:1. For the purpose of this investigation we focus on the E-center peaks in the temperature range $200-230 \mathrm{~K}$. It is evident from spectra (c) and (d) in Fig. 1 that there is little difference in the peak positions of the V-P and (V-P)+(V-As). On the other hand, the peak positions on spectra containing Sb E-centers (curves (a) and (b)) are clearly shifted to lower temperatures, indicating that the energy level of $\mathrm{V}-\mathrm{Sb}$ are shallower than those of V-P and V-As. To investigate this in more detail, Laplace DLTS measurements were performed in the temperature range 200-250 K. For Laplace DLTS the transient is recorded at a fixed temperature and as many averages are recorded as is practically possible to maximize the signal-to-noise ratio that ideally should exceed 1000 to separate closely spaced layers such as the family of E-centers. 


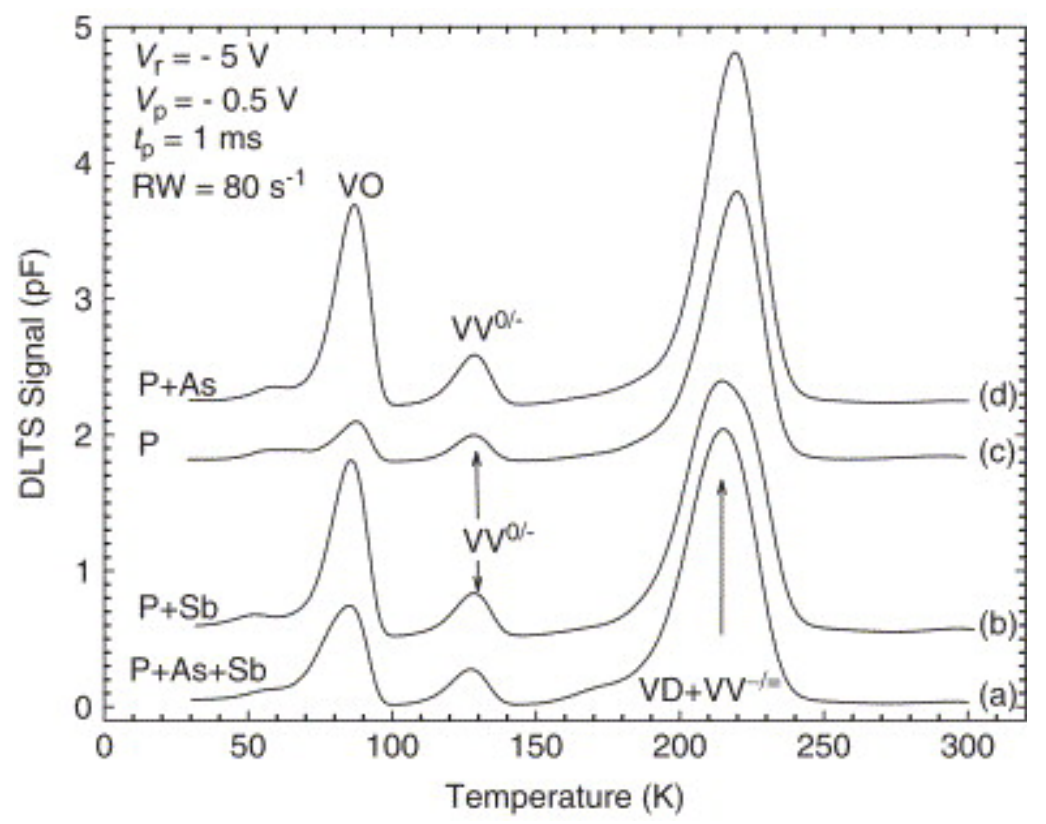

Fig. 1. DLTS spectra of electron-irradiated $n$-Si doped with $\mathrm{P}$ (curve (c)), $\mathrm{P}$ and $\mathrm{Sb}$ (curve (b)), P and As (curve (d)) and P, Sb and As (curve (a)). All spectra were recorded under conditions as indicated in Fig. 1.

In Fig. 2(a)-(d), we show the Laplace DLTS spectra of S1-S4 recorded at 225 K. First consider curve (a), recorded from sample $\mathrm{S} 1$, where the only dopant is P. Here the major peak is that of the $\mathrm{V}-\mathrm{P}$ center while the peak of the $\mathrm{V}-\mathrm{V}^{-/=}$is smaller, as expected, but well separated from that of the $\mathrm{V}-\mathrm{P}$. The ratio of the amplitudes of the $\mathrm{V}-\mathrm{P}$ to $\mathrm{V}-\mathrm{V}^{-/=}$is about 7:1, consistent with the relative peak height of the di-vacancy and E-center from conventional DLTS and shown in curve (c) in Fig. 1. Curve (b) in Fig. 2 represents the Laplace DLTS spectrum of sample S2 which contained P and Sb in about the same concentrations. Here we notice that the peaks of $\mathrm{V}-\mathrm{P}$ and $\mathrm{V}-\mathrm{V}^{-/=}$have merged to form a broad peak but the new peak at an emission rate of about $850 \mathrm{~s}^{-1}$ is that of the $\mathrm{V}-\mathrm{Sb}$ center. The ratio of the emission rates of $\mathrm{V}-\mathrm{Sb}$ to $\mathrm{V}-\mathrm{P}$ is about 5-6, i.e., well above the reliability limit of 2 and therefore they may be used with confidence to extract the "signature" of at least the V-Sb. Next, consider curve (c), recorded from sample S3 containing $\mathrm{P}$ and As dopants. As in the case of $\mathrm{S} 2$ the $\mathrm{V}-\mathrm{P}$ and $\mathrm{V}-\mathrm{V}^{-/=}$peaks are totally merged but the $\mathrm{V}-\mathrm{As}$ peak is well separated from that of the $\mathrm{V}-\mathrm{P}$. However, the ratio of the emission rates of $\mathrm{V}-\mathrm{As}$ to $\mathrm{V}-\mathrm{P}$ is about 1.8, i.e., slightly below two, and therefore there may be some inaccuracy in determining the "signature" of V-As. Finally, the spectrum in curve (d) for sample S4 shows that Laplace DLTS successfully separated the peaks of $\mathrm{V}-\mathrm{P}, \mathrm{V}-\mathrm{As}$ and $\mathrm{V}-\mathrm{Sb}$ in the same sample. Although the ratios of the emission rates of $\mathrm{V}-\mathrm{Sb}$ to $\mathrm{V}-\mathrm{As}$ and $\mathrm{V}-\mathrm{As}$ to $\mathrm{V}-\mathrm{P}$ are both larger than 2 in this figure where spectra were recorded at $225 \mathrm{~K}$, this was not the case for some other temperatures and the signatures extracted for the E-centers from this sample varied noticeably from those obtained where only one or two E-centers were present. 


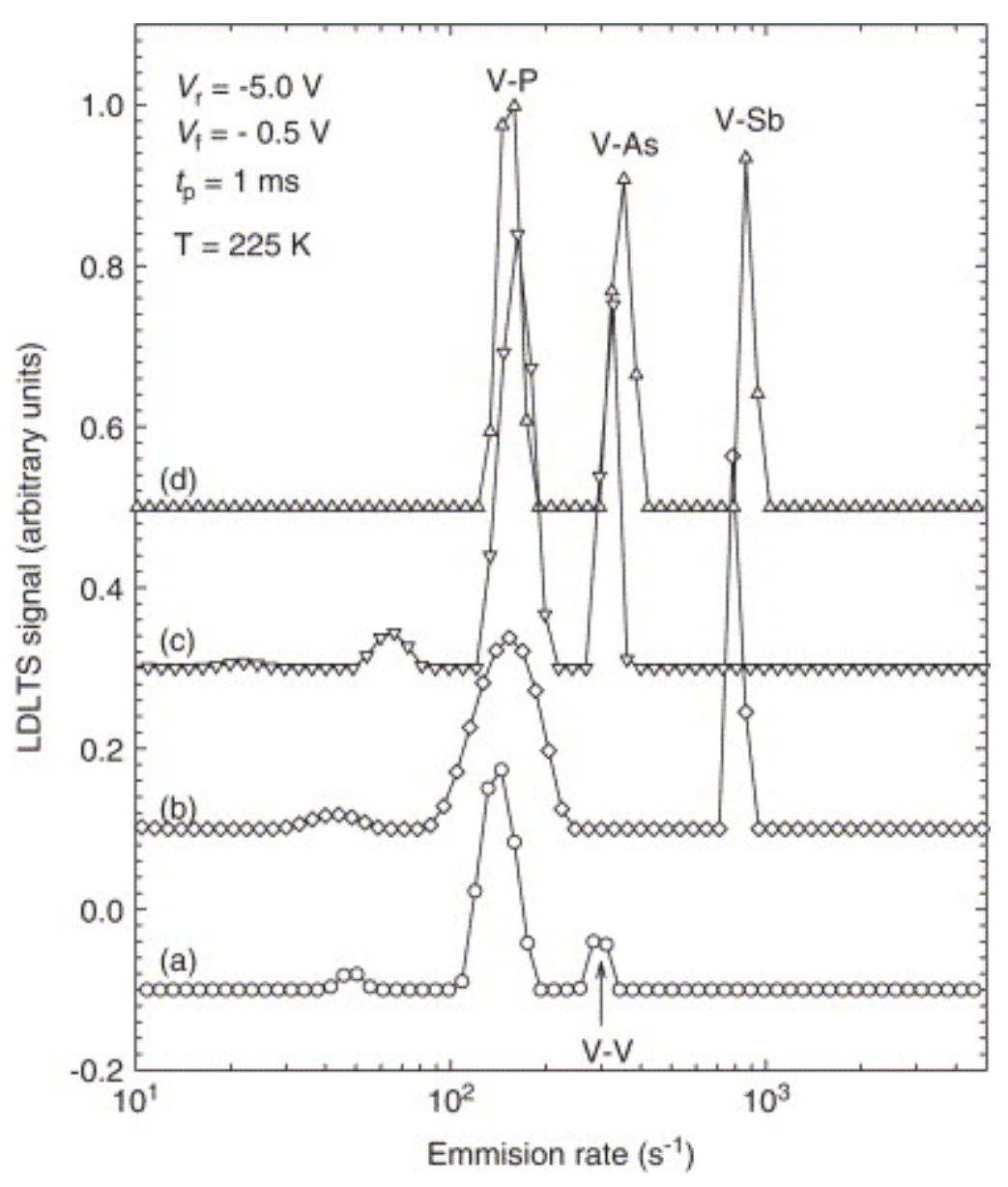

Fig. 2. Laplace DLTS spectra, recorded at $225 \mathrm{~K}$ of electron-irradiated $n$-Si doped with $\mathrm{P}$ (curve (a)), P and Sb (curve (b)), P and As (curve (c)) and P, Sb and As (curve (d)). All spectra were recorded under conditions as indicated in Fig. 2.

The activation enthalpies, $E_{\mathrm{T}}$, and apparent capture cross-sections, $\sigma_{\mathrm{a}}$, were extracted from the slope and intercept of Arrhenius plots of $\log \left(T^{2} / e\right)$ vs. 1000/T, respectively, where $e$ is the emission rate at temperature $T$. In Fig. 3, we present the Arrhenius plots for the E-centers in samples S1-S4. The values obtained for $E_{\mathrm{T}}$ and $\sigma_{\mathrm{a}}$ are summarized in Table 2. For sample $\mathrm{S} 1$ we obtained from the $E_{\mathrm{T}}$ and $\sigma_{\mathrm{a}}$ of the $\mathrm{V}-\mathrm{P}$ center as $0.458 \mathrm{eV}$ and $1.2 \times 10^{-14} \mathrm{~cm}^{2}$, respectively. The Arrhenius plot in Fig. 3 of the V-P in sample S2 lies close to that of the V-P in S1 and we obtained the "signature" of V-P in sample S2 as $E_{\mathrm{T}}=0.442 \mathrm{eV}$ and $\sigma_{\mathrm{a}}=6.2 \times 10^{-15} \mathrm{~cm}^{2}$, respectively. For the $\mathrm{V}-\mathrm{Sb}$ in this sample, we found $E_{\mathrm{T}}=0.401 \mathrm{eV}$ and $\sigma_{\mathrm{a}}=3.3 \times 10^{-15} \mathrm{~cm}^{2}$, respectively. This lower activation enthalpy of the $\mathrm{V}-\mathrm{Sb}$ than of the $\mathrm{V}-\mathrm{P}$ is consistent with the conventional DLTS spectrum from this sample (curve (b) in Fig. 1) where a broadening towards the low temperature was observed when $\mathrm{Sb}$ was added to the matrix. It should be pointed out that the ratio of the emission rate of $\mathrm{V}-\mathrm{Sb}$ to $\mathrm{V}-\mathrm{P}$ was about 5-6, so the peaks were far enough from each 
other so as to not interfere with each other and therefore the values of $E_{\mathrm{T}}$ and $\sigma_{\mathrm{a}}$ are reliable.

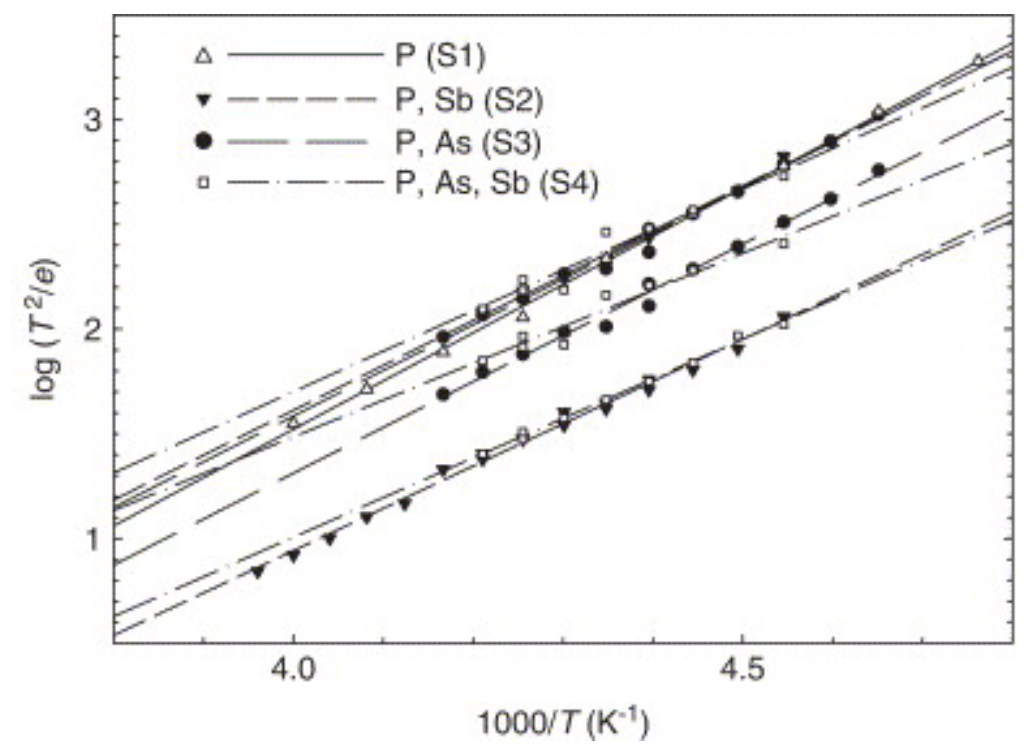

Fig. 3. Arrhenius plots of E-centers in electron-irradiated $n$-Si doped with P (solid lines and up-triangles), $\mathrm{P}$ and $\mathrm{Sb}$ (short lines and solid down triangles), $\mathrm{P}$ and As (solid circles and long-dashed lines) and $\mathrm{P}, \mathrm{Sb}$ and As (open circles and dash-dot-dash lines). 
Table 2.

Activation enthalpies, $E_{\mathrm{T}}$, apparent capture cross-sections, $\sigma_{\mathrm{a}}$, and the temperature range for measurements, $T_{\text {range}}$, of E-centers in samples $\mathrm{S} 1-\mathrm{S} 4$

\begin{tabular}{|l|l|l|l|l|l|}
\hline Defect & & S1 (no0) & S2 (no8) & S3 (no6) & S4 (no7) \\
\hline V-P & $E_{\mathrm{T}}(\mathrm{eV})$ & $0.458 \pm 0.005$ & $0.442 \pm 0.010$ & $0.433 \pm 0.010$ & $0.413 \pm 0.020$ \\
\hline & $\sigma_{\mathrm{a}}\left(\mathrm{cm}^{2}\right)$ & $1.2 \times 10^{-14}$ & $6.2 \times 10^{-15}$ & $3.4 \times 10^{-15}$ & $1.1 \times 10^{-15}$ \\
\hline & $T_{\text {range }}(\mathrm{K})$ & $185-250$ & $220-240$ & $215-240$ & $225-237.5$ \\
\hline $\mathrm{V}-\mathrm{As}$ & $E_{\mathrm{T}}(\mathrm{eV})$ & - & - & $0.435 \pm 0.010$ & $0.398 \pm 0.020$ \\
\hline & $\sigma_{\mathrm{a}}\left(\mathrm{cm}^{2}\right)$ & - & - & $6.8 \times 10^{-15}$ & $1.0 \times 10^{-15}$ \\
\hline & $T_{\text {span }}(\mathrm{K})$ & - & - & $215-240$ & $225-237.5$ \\
\hline $\mathrm{V}-\mathrm{Sb}$ & $E_{\mathrm{T}}(\mathrm{eV})$ & - & $0.401 \pm 0.010$ & - & $0.371 \pm 0.020$ \\
\hline & $\sigma_{\mathrm{a}}\left(\mathrm{cm}^{2}\right)$ & - & $3.3 \times 10^{-15}$ & - & $1.3 \times 10^{-15}$ \\
\hline & $T_{\text {span }}(\mathrm{K})$ & - & $220-255$ & - & $222.5-237.5$ \\
\hline & & & & & \\
\hline
\end{tabular}

As pointed out above, the ratio of the emission rates of the $\mathrm{V}-\mathrm{P}$ and $\mathrm{V}-\mathrm{As}$ in $\mathrm{S} 3$ is close to two and although their magnitudes are almost the same, the exact positions of the peaks should be viewed with caution. As it is, the "signature" of the V-P center calculated for sample S3 from Fig. 3 is $E_{\mathrm{T}}=0.433 \mathrm{eV}$ and $\sigma_{\mathrm{a}}=3.4 \times 10^{-15} \mathrm{~cm}^{2}$. These are slightly different from the values calculated from sample S1 where only the V-P center was present. We attribute this difference to the fact that these defects have an emission rate ratio that borders on the reliability limits of quantitative LDLTS. The "signature" of the $\mathrm{V}-\mathrm{As}$ center was found to be $E_{\mathrm{T}}=0.435 \mathrm{eV}$ and $\sigma_{\mathrm{a}}=6.8 \times 10^{-15} \mathrm{~cm}^{2}$. The same consideration as above should also apply to the accuracy limits of its signature: the closeness of the two peaks may render slightly inaccurate results although their amplitudes are almost the same. Finally, consider the Arrhenius plots in Fig. 3 of V-P, $\mathrm{V}-\mathrm{As}$ and $\mathrm{V}-\mathrm{Sb}$ in sample S4. Although we observed three peaks at several different temperatures in the Laplace DLTS spectra for sample S4, the Arrhenius plots of these defects show that the signatures of these defects have been significantly distorted to yield quite different values of $E_{\mathrm{T}}$ and $\sigma_{\mathrm{a}}$ (Table 2) compared to the samples where only the $\mathrm{V}-\mathrm{P}$ or $\mathrm{V}-\mathrm{P}+\mathrm{V}-\mathrm{As}$ or $\mathrm{V}-\mathrm{P}+\mathrm{V}-\mathrm{Sb}$ were present.

\section{Conclusions and summary}

In the sample that contains only $\mathrm{P}$ the signature of $\mathrm{V}-\mathrm{P}$ was determined accurately without noticeable interference of the $\mathrm{V}-\mathrm{V}$ signal that is much smaller than that of $\mathrm{V}-\mathrm{P}$, 
where $\mathrm{P}$ and $\mathrm{Sb}$ are both present the $\mathrm{V}-\mathrm{P}$ and $\mathrm{V}-\mathrm{Sb}$ peaks could clearly be distinguished and reliable "signatures" were determined for these defects. The signature of the V-P in this sample closely matches that of the V-P in the sample S1 where only P was present. The $\mathrm{V}-\mathrm{V}^{-/=}$signal could not be distinguished from that of the $\mathrm{V}-\mathrm{P}$ in this sample. In the sample that contains $\mathrm{P}$ and As the ratio of the emission rates of the $\mathrm{V}-\mathrm{P}$ and $\mathrm{V}-\mathrm{As}$ is slightly below two and their amplitudes are almost the same. The signature that we obtained for $\mathrm{V}-\mathrm{P}$ is also quite close to that of the $\mathrm{V}-\mathrm{P}$ in sample $\mathrm{S} 1$ where only the $\mathrm{V}-\mathrm{P}$ was present yielding a value of $E_{\mathrm{T}}$ that is about $5 \%$ lower than that of the V-P in sample $\mathrm{S} 1$. The spectra for sample $\mathrm{S} 4$ that contains $\mathrm{P}, \mathrm{Sb}$ and As clearly showed three wellseparated peaks of approximately the same amplitude. However, a more detailed investigation via Arrhenius plots revealed that the "signatures" calculated from this data deviate significantly from those of the samples where only two dopants ( $\mathrm{P}$ and As or $\mathrm{P}$ and $\mathrm{Sb}$ ) were present. For example, the $E_{\mathrm{T}}$ for $\mathrm{V}-\mathrm{P}$ in this sample is about $10 \%$ lower than that of V-P in the sample containing only P. In this case Laplace DLTS could be used to qualitatively distinguish between the three defects but could not be used for an accurate quantitative analysis of their "signatures".

In summary, we have studied by conventional and Laplace DLTS the E-centers in four sets of Si samples that contained (i) only P, (ii) P and Sb, (iii) P and As, and (iv) P, Sb and As. For cases (i) and (ii) accurate "signatures" could be obtained for the V-P and V$\mathrm{Sb}$ because in case (ii) the ratio of the peak positions is much larger than 2 which is required for reliability. In case (iii) the ratio of the peak positions of $\mathrm{V}-\mathrm{As}$ and $\mathrm{V}-\mathrm{P}$ is slightly below 2 and therefore there is some inaccuracy in their "signatures". In case (iv) the signals of the three E-centers could be clearly separated but the "signatures" deviated noticeably from those obtained where only one or two E-centers were present. We conclude that Laplace DLTS can be used with confidence to accurately characterize Ecenters if one or two species are present in the same sample and to clearly distinguish between $\mathrm{V}-\mathrm{P}, \mathrm{V}-\mathrm{Sb}$ and $\mathrm{V}-\mathrm{As}$ in the same sample.

As a result it is quite evident that the activation enthalpies of the E-centers are ordered in the sense that the energy increases with decreasing size of the group $\mathrm{V}$ ion and more directly with the increasing electro-negativity of the group $\mathrm{V}$ component. The small magnitude of the change reflects the rather weak influence the electron affinity of the group $\mathrm{V}$ ion has on the activation enthalpy of the complex and the dominance of the vacancy like nature of the E-center. 


\section{References}

[1] E.L. Elkin and G.D. Watkins, Phys. Rev. 174 (1968), p. 881.

[2] A.O. Evwaraye and E. Sun, J. Appl. Phys. 47 (1976), p. 3776.

[3] A.O. Evwaraye, J. Appl. Phys. 48 (1977), p. 1840.

[4] L. Dobaczewski, P. Kaczor, I.D. Hawkins and A.R. Peaker, J. Appl. Phys. 76 (1994), p. 194.

[5] L. Dobaczewski, A.R. Peaker and K.B. Nielsen, J. Appl. Phys. 96 (2004), p. 4689.

[6] R.C. Newman, J. Phys.: Condens. Matter 12 (2000), p. R335. 